starting from the presumption that adult ADHD is a useful and valid category. There are numerous articles that provide an opposing point of view. With regard to the randomised trials of drug treatment, since National Institute for Health and Clinical Excellence guidelines are so influential and have endorsed the validity and drug treatment of adult ADHD, it is important to point out the evidence on which these conclusions were reached. We also refer to a meta-analysis of trials of methylphenidate, which found no significant difference in parallel group randomised trials, and the Cochrane review of amphetamines quoted by Dr Bhattacharya also found a lack of evidence of long-term benefit and a high risk of bias.

We do not see that our presentation of the genetic data differs substantially from the way it is presented by Kooij et al, also quoted in Dr Bhattacharya's letter. In any case, we know that most molecular genetic findings are not replicated. The references we used to support the idea that there have been challenges to the concept of childhood ADHD include a book by one of us that was referred to because it reviews the literature in this area, and an article challenging the consensus statement on ADHD that was authored by 32 authors, as well as ourselves.

Dr Bhattacharya and Dr Lepping highlight the problem of comorbidity. The idea that the frequent comorbid conditions are distinct problems, or secondary to ADHD symptoms, rather than competing ways of conceptualising the same problems, is simply an assumption that follows from accepting the diagnosis of adult ADHD. Inattentiveness is too vague a concept to be used to clarify the diagnosis and, given the inclusive nature of inattentiveness 'symptoms', is likely to be identified by most people with mental health problems, as well as many without.

In response to Dr Lepping, studies on levels of the dopamine transporter in ADHD are contradictory, despite the consensus. ${ }^{1}$ Stimulants have well-documented psychoactive effects, and so it is not surprising that they change behaviour in the short term, producing large effects sizes. What is at stake is whether or not they help people in the long term. Evidence in children is not convincing. The Mutimodal Treatment Study of Children with ADHD (the MTA study), which has been criticised on many grounds, found only marginal benefits of a 'medication management' package over behavioural therapy alone or routine community treatment (often including stimulants) at 14 months. ${ }^{2}$ At 3 years there was no difference between the groups, and there was no effect of compliance. ${ }^{3}$ At 8-year follow-up, analysis according to randomised group and actual medication used failed to show any advantage for medication. ${ }^{4}$ Other naturalistic follow-up studies have also failed to demonstrate any advantage for long-term medication in children ${ }^{5}$ and, as we describe in our paper, the evidence in adults is even weaker. Without evidence of long-term benefits, we suggest there is no justification for prescribing medication.

1 Varrone A, Halldin C. Molecular imaging of the dopamine transporter. J Nucl Med 2010; 51: 1331-4.

2 The MTA Cooperative Group. A 14-month randomized clinical trial of treatment strategies for attention-deficit/hyperactivity disorder. The MTA Cooperative Group. Multimodal Treatment Study of Children with ADHD. Arch Gen Psychiatry 1999; 56: 1073-86.

3 Jensen PS, Arnold LE, Swanson JM, Vitiello B, Abikoff HB, Greenhill LL, et al. 3-year follow-up of the NIMH MTA study. J Am Acad Child Adolesc Psychiatry 2007; 46: 989-1002.
4 Molina BS, Hinshaw SP, Swanson JM, Arnold LE, Vitiello B, Jensen PS, et al. MTA at 8 years: prospective follow-up of children treated for combined-type ADHD in a multisite study. J Am Acad Child Adolesc Psychiatry 2009; 48: 484-500.

5 Government of Western Australia Department of Health. Raine ADHD Study: Long-term Outcomes Associated with Stimulant Medication in the Treatment of ADHD in Children. Government of Western Australia Department of Health, 2010.

For the full list of references to this letter, please email the authors.

Joanna Moncrieff, senior lecturer, Department of Mental Health Sciences, University College London, email: j.moncrieff@ucl.ac.uk, Sami Timimi, consultant in child and adolescent psychiatry, Lincolnshire Partnership NHS Foundation Trust, Sleaford, Lincolnshire, UK.

doi: $10.1192 / p b .35 .12 .474 a$

\section{Disclosure of psychiatric records}

The article by Thompson ${ }^{1}$ contains many errors and misleading statements. To begin with, Thompson says that requests from courts for medical records 'are issued by letter'. Courts do not issue requests; they make orders (sometimes referred to as directions). Such orders are never couched in the form of a letter. An order requiring the production of medical records is normally addressed to one of the parties to the proceedings. Such an order would be likely to be addressed to a hospital, National Health Service trust or other such body, or to an individual doctor only when that hospital, trust, other body or doctor had previously failed to disclose the records sought.

The author says that a psychiatrist has the duty to 'seek legal advice from the trust if it appears that clinical information is being requested that is not relevant to the legal issue at stake'. The psychiatrist has no such duty and would be well advised to refrain from expressing any opinion as to whether the records sought are relevant to the issues in the case, and still more so from acting on any such opinion. The psychiatrist is unlikely to have a full appreciation of the legal issues involved. Whether or not he has a correct understanding of the issues, to refuse to release medical records whose disclosure has been directed, on the ground that they are considered not to be relevant to the case clearly defies the authority of the court and is certain to arouse the ire of the judge. An unsympathetic judge might consider it to be contempt of court.

Thompson states that when medical records are released in compliance with a court order, 'third-party information must be removed from case notes'. This is not the case. Section 35 of the Data Protection Act 1998 provides, inter alia: '(1) Personal data are exempt from the non-disclosure provisions where the disclosure is required by or under any enactment, by any rule of law or by the order of a court'. Accordingly, when medical records are released in response to an order of a court they must be disclosed in their entirety, as stipulated in the order. No items should be omitted.

Thompson further says that the psychiatrist's duty of confidentiality 'is not automatically waived by a request from court'. She suggests that a patient could complain to the General Medical Council (GMC) of a breach of confidentiality and that the Council would investigate the complaint. The GMC's guidance on confidentiality states, at paragraph 21: 'You must disclose information if ordered to do so by a judge or presiding officer of a court'. ${ }^{2}$ This, of course, does no more than state the law of the land. However, it is clear that no 
complaint could lie against a doctor merely on the ground that he had complied with an order of a court. Any attempt by the GMC to proceed against a doctor in these circumstances would quickly be thrown out by the courts, on the application of the doctor's medical defence organisation, as an abuse of process.

It is clearly good practice to inform a patient that an order requiring the release of his records has been received, and has to be complied with. Thompson suggests that a psychiatrist might be instructed by 'court officials' not to inform the patient. It is difficult to envisage any situation that is not fanciful in which a court might be minded to direct that an individual should not be informed that an order requiring the release of his medical records had been made. As judicial proceedings and court orders are ordinarily in the public domain, it would obviously be necessary for the court also to direct that references to these matters should be omitted from the public record of the proceedings. While disclaiming any legal expertise, I would doubt that any such powers exist, save in the most exceptional circumstances, such as cases involving issues of national security.

Thompson says that the Civil Evidence Act 1995 calls the process by which psychiatrists are requested to attend court 'being served with a witness summons'. The Civil Evidence Act 1995 does not deal with witness summonses (it is principally concerned with the admissibility of hearsay evidence) and includes no such statement. The article includes a table (Box 1) headed 'Standards expected by courts of an expert witness'. This is an adaptation of recommendations made by the Academy of Medical Royal Colleges in $2005 .^{3}$ The judiciary have not published any list of qualifications required to be possessed by expert witnesses, medical or other. The heading is accordingly misleading.

1 Thompson AE. 'You are instructed to prepare a report ... ' How to make sound decisions about whether to accept or decline medico-legal work. Psychiatrist 2011; 35: 269-72.

2 General Medical Council. Confidentiality. GMC, 2009.

3 Academy of Medical Royal Colleges. Medical Expert Witnesses: Guidance from the Academy of Medical Royal Colleges. AMRC, 2005.

lan G. Bronks FRCP (Ed.), FRCPsych, retired consultant psychiatrist, 64 Broadway, Duffield, Derbyshire DE56 4BU, UK, email: ian.bronks@talktalk.net

doi: $10.1192 / \mathrm{pb} .35 .12 .475$

\section{Author's response}

Dr Bronks takes issue with a number of matters in my paper and helpfully includes extracts from source materials to orientate the reader to his corrections and clarifications. While bowing to Dr Bronk's superior knowledge of legal detail, I stand by several of my assertions which reflect decisions I have been supported to make in my clinical practice. I suggest that this exchange illustrates that decisions made in medico-legal work are always open to challenge, and psychiatrists should have a low threshold for seeking advice on a case-by-case basis about medico-legal matters.

Anne E. Thompson, Consultant Child and Adolescent Psychiatrist, Horizon Centre, Lincolnshire, Lincolnshire Partnership NHS Foundation Trust, UK, email: annelizthompson@aol.com

doi: $10.1192 /$ pb.35.12.476

\section{Perspective of a foundation year 2 doctor on psychiatry in the foundation programme}

As a foundation year 2 (F2) doctor currently rotating through a pilot post in psychiatry in the Northern Deanery, I read 'Improving psychiatry training in the Foundation Programme' with great interest. I am in broad agreement with the authors that psychiatry placement in the foundation programme is of great benefit both to the new doctor in terms of experience and to the profession as a whole, boosting awareness of the specialty and recruitment. However, based on my experience so far in psychiatry I have become aware of several possible detrimental effects of psychiatry as an early foundation placement for F1 doctors.

In their article, Welch et al stated that there may be 'difficulties maintaining medical skills' and 'acquiring acute medical competences'. A newly qualified F1 doctor working in a medical or surgical job experiences an extremely steep learning curve as they develop skills in grappling with acute medical problems and basic everyday tasks such as prescribing medications and fluids, phlebotomy, cannulation and traditional ward rounds. Although some of these experiences are common to psychiatry, the role of the foundation doctor in the mental health multidisciplinary team is quite different and unique. Often the mental health multidisciplinary team looks on the foundation doctor for medical advice and management of patients with physical health problems. I perceive two problems with a newly qualified F1 doctor rotating through psychiatry during their first or even second placements. First, the F1 doctor is unlikely to be able to complete the steep learning curve for practical tasks at the beginning of their year, when general hospitals offer more support and are often more lenient as the new doctor develops basic skills. This could leave the F1 doctor with feelings of incompetence and possibly lead to them being viewed so by peers, seniors and ward teams when commencing a medical or surgical job later in their first year. Second, without a good grounding in dealing with common medical problems with supervision from a medical team in a general hospital, the F1 doctor is likely to lack skills and confidence in the management of physical health problems on a psychiatric ward. Therefore the benefit for the mental health multidisciplinary team of having a foundation doctor with some competence in managing physical problems is lost and the doctor may feel out of depth. Doing medical on-call work may help to minimise these effects, but infrequent duties may exacerbate lack of confidence and F1 doctors may feel thrown in at the deep end during out-of-hours work compared with peers working daily in medical jobs. I feel it is the daily work of an F1 doctor on medical or surgical wards that allows for these skills to be developed and consolidated.

Therefore, it is my opinion that F1 doctors should not be rotating through 3- to 4-month psychiatry placements for the first 8 months of their training year, but that a placement would be beneficial for the trainee in the later months once a firm medical foundation is in place. This would allow the trainee to approach their psychiatry placement with more confidence and therefore value the experience more, while not being detrimental to their initial medical training as a whole. However, given that experience in psychiatry is important in terms of recruitment and allowing foundation trainees to experience the specialty as a graduate, ${ }^{2}$ in addition to longer 